\title{
A Story Woven in Time: How Spider Silk Can Exemplify Evolutionary Theory
}

\author{
Spider Silk, Leslie Brunetta \& Catherine L. Craig. New Haven: Yale University Press, \\ 2010. Pp. viii+229. H/b $\$ 30.00$
}

\author{
Rachael A. Carmen
}

Published online: 2 March 2012

(C) Springer Science+Business Media, LLC 2012

"Silk and the evolvable nature of the genes that dictate it have enabled spiders to stake a claim in the land for hundreds of millions of years and they are likely to do so for hundreds of millions of years to come" (p. 190).

Spiders and their silk are the products of millions of years of evolution, and, according to Leslie Brunetta and Catherine Craig, they provide us with a unique peephole into the world of biological evolution. Spider Silk teaches the reader about evolutionary theory while explaining the evolution of spiders, their silk, and the intricacies of various types of webs. From an early possible common ancestor to the gamut of modern day spider species, the authors paint a vivid picture of spider life in the last 400 million years in a mere 229 pages and at the very least, make readers reconsider their aversion to spiders. But this book is so much more than just a book on spiders; it explains evolutionary theory beautifully and keeps the reader enticed throughout the book with fascinating stories about everything from the etymology of the term Arachnid to explaining exactly how accurate E.B. White was when he wrote Charlotte's Web in 1952 - and yes, they even discuss Spider Man. Overall, Spider Silk is fascinating and is written for a large audience, so this book is recommended for virtually anyone that would like a better understanding of evolution while learning about the fascinating lives of spiders.

Spider Silk starts strong before chapter one-with the preface. The reader is prepped for the rest of the book by building an intellectual foundation with evolutionary theory and spider anatomy, eventually coupling the two together just before the reader reaches chapter one. Chapter one,

\section{R. A. Carmen $(\square)$}

The State University of New York at New Paltz,

Psychology Department 314 JFT, Humanities 2A,

1 Hawk Drive,

New Paltz, NY 12561, USA

e-mail: Rachael.Carmen@gmail.com entitled "Fossils," starts where any good story about evolution should begin: in the fossils. Spiders, along with scorpions, mites, ticks, and horseshoe crabs make up the subphylum Chelicerata (trigonotarbids and sea scorpions were once members of this subphylum, but have since gone extinct). Along with the Chelicerata, Pycnogonida (sea spiders), Myriapoda (centipedes, millipedes, etc.), Crustacea (lobsters, barnacles, etc.), and Hexapoda (insects, entognaths) they make up the Phylum Arthropoda. The term Chelicerata comes from the unifying feature of this subphylum - chelicerae (jaws) (members of this subphylum all lack antennae as well). Chelicerates are thought to have most likely descended from aquatic arthropods that lived during the Cambrian period.

Leslie Brunetta and Catherine Craig use their creative imagery to paint a picture of the colorless earth 400 million years ago when the landscape was comprised mostly of cooled lava, ash, and rocks. Aquatic arthropods began to move to the drier reaches of the shoreline to evade predators in the water. Eventually, gills evolved into book lungs (a primitive form of lungs that are made up of gill-like sheets of tissue) and spinnerets. In order for an animal to be considered a spider, it must, by definition, have spinnerets to produce silk. The first evidence of a spider-like animal was found in fossils (dating to about 400 million years ago) of Trigonotarbids, one of the most common land animals during this time. Much like modern day spiders, Trigonotarbids possessed a two-part body, eight legs, chelicerae, and pockets on the underside of their abdomen that contained book lungs. But unlike spiders, Trigonotarbids could not produce silk, and thus, cannot be considered the first true spider. Another fossil, Attercopus fimbriunguis, dates back to about 380 million years ago, and unlike the Trigonotarbids, there is evidence pointing to the idea that these animals produced silk. This silk came from spigots that were located on abdominal plates of the exoskeleton-not spinnerets, and 
therefore, Attercopus could not be considered the first true spider either. Leslie Brunetta and Catherine Craig explain that Liphistius desultor was the term coined for a 290 million year old fossil of a Mesothelae - the oldest surviving lineage of spiders. This spider showed a unique mix of ancestral and derived traits: its front half was similar to modern day spiders, yet its abdomen was segmented like the ancestral arthropods (Trigonotarbids and Attercopus). Modern day spiders are classified under the order Araneae, which is made up of two suborders: Mesothele (meaning "middle teat") and Opisthothelae (meaning "posterior teat"). Mygalomorphae (tarantulas and their relatives) and Araneomorphae ("true" spiders) make up the Opisthothelae suborder. From an evolutionary perspective, Mesotheles are incredibly fascinating because they are considered "living fossils" due to the fact that they are almost identical to the Mesothele fossil that dates back 290 million years. The point here is that in the first two chapters, the reader gets a very good sense of how, when, and why the first spiders came into existence. Leslie Brunetta and Catherine Craig do an impressive job cramming countless facts into the first two chapters, all while keeping the reader interested by using a lucid writing style to paint landscapes of a very different world, millions of years ago.

Chapter three, entitled "Chance and Change" gets into the history behind the theory of evolution (i.e. the lives of Charles Darwin and Alfred Russell Wallace) and subsequently, the basic tenets of evolutionary theory. This chapter could definitely stand alone as a gem for evolutionary scholars; yet, the connection with spiders that the authors make throughout the book is so fascinating that reading the book in its entirety is highly recommended. Simply put, anyone could pick up this book and learn what evolution is all about. Add in fascinating facts about the lives of spiders, and the reader's understanding of evolution becomes more real. By coupling the evolution of spiders and their silk with evolutionary theory, the authors give readers a physical representation of something that is considerably unseen. Leslie Brunetta and Catherine Craig also explain the mechanisms behind evolution (natural selection, gene flow, genetic drift, mutation) very well, in addition to colloquially mentioning all the pre- and post-zygotic barriers to reproduction through the world of spider speciation. Once the authors have successfully prepped the reader for the remainder of the book, the various chapters begin to tell a fascinating story of the evolution of spiders and the intricacies of their silk.

Chapter four, entitled "Outward and Upward" begins the story of how spiders became what they are today. Between 363 and 250 million years ago, a seemingly flat monochrome world began changing drastically: plant life began to flourish. This growth of flora consequentially began to change the atmospheric oxygen levels, causing them to rise to an all-time high of nearly $30 \%$ (today our oxygen levels are about $21 \%$ ). These trends began to reverse and the earth experienced the Permian mass extinction (the most devastating extinction in the fossil record). Leslie Brunetta and Catherine Craig explain that nine out of every ten species died off during this time... but not spiders. By the end of the Triassic period (200 million years ago), ferns and trees began spreading and insects and spiders experienced a decrease in predators - making it possible for the diversification of insect and spider species. During this time, spider silk and web weaving began to get interesting: what was once used to line burrows was now being used to make extensions of burrows and even trap doors. Very basically: The first instances of the diversification of spider silk came about in the form of trip lines that were used to alert the spider that a predator was present, eventually leading to sheet webs that doubled as predator and prey detectors. Leslie Brunetta and Catherine Craig explain that as spider species began to find new and innovative ways to use their silk, natural selection favored these individuals and made it possible for the ancestors of these species to come up with even more fascinating uses for their silk.

Chapter five, entitled "Triumph over Thin Air," explains how some spider species began to move from underground burrows to suspended webs in the air. The authors explain that Araneomorphae, the second infraorder in the suborder Opisthothelae, is comprised of spider species that are most commonly known today. Leslie Brunetta and Catherine Craig explain that the appearance of major ampullate silk (aka dragline) seems to correlate with the beginning of the third major phase in spider evolution: the araneomorph phase. Without this variation of silk, spiders would have been unable to be so successful in the air. Araneomorphs, unlike mesotheles and mygalomorphs do not need an anchor point to spin their silk - an interesting evolutionary advantage for spiders that populate areas high up in the air: “...the early araneomorphs' 'revolutionary' leap into aerial web construction can be seen not as a radical departure from spiders' previous habits but as a point farther along a continuum of silk making and silk use" (p.64). And seamlessly, just as the reader begins to wonder about the inner workings of spider silk, the authors introduce seemingly complicated genetics in style understandable to a lay audience in the subsequent chapter.

The remainder of the book goes into exquisite detail in regard to the fascinating lives of various spiders and how natural selection has shaped their silk. For instance, the onset of major ampullate silk gave rise to the ability of araneomorph spiderlings (and some adults) to fly through the air via "ballooning." If they find a high point and release puffs of major ampullate silk, the wind will catch and lift these spiderlings to far-off distances-something that is extremely advantageous in areas that are overpopulated. Leslie Brunetta and Catherine Craig also discuss instances 
of coevolution in very fascinating ways. For example, wasps are a predator to spiders and they have way better stamina. Wheel spiders evolved the ability to straighten out their limbs, turn horizontally, and speed down hills at a rate equivalent to cars moving at 137 miles per hour to avoid falling victim to "a fate worse than death" (you will have to read the book to find out what this means). Shockingly, the authors also explain that some spider species actually eat other spiders. One genus of jumping spiders, Portia fimbriata will spend countless hours plucking other spiders' webs in an intricate dance to mimic prey; the target spider then comes out expecting dinner but instead becomes dinner itself. Other spiders have become expert marksmen: the bolas spiders will spin out a single line of silk with a sticky blob at the end of it to swing through the air to catch moths.

As Leslie Brunetta and Catherine Craig guide the reader through the world of spiders, they weave in evolutionary theory seamlessly_-introducing a spider species' fascinating quirks on one page, and then explaining its evolutionary relevance on the next. At the very least, the world of spiders is incredibly fascinating, but this book does not deserve the very least. The authors give the reader an incredible window into the basic tenets of evolutionary theory: Because a spider's survival is so independent on its silk, and because spider silks are protein and protein can be traced directly to genes, the world of spider silk can help exemplify the basic mechanisms behind evolution. The changes in silk genes that came about due to small genetic changes sometimes resulted in functional benefits (e.g., major ampullate silk) that were incredibly advantageous. Basically, small genetic changes can have a large impact on the individual - and the authors make this point throughout the book beautifully.

Spider Silk is an educational, thoughtful, fun, and compelling read. Each chapter presents the reader with a logical progression of the spider species' evolution-from early common ancestors millions of years ago to spiders we come into contact with everyday. Leslie Brunetta and Catherine Craig make great use of examples and have even included a section in the middle of the book with pictures of some of the most interesting spiders and their webs (there is nothing better than being able to see a picture of a gladiator spider after you have learned about its peculiar hunting techniques). Because of the link between genes, proteins, spider silk, and a spider's reliance on that silk, this book pieces together a way for the reader to physically conceptualize evolutionary theory. After reading this book, it is hard not to stop and marvel at the complexity of spiders and their webs. 